\title{
Restoring shine on the Big Apple
}

\section{New York City}

Home to seven medical schools and to Rockefeller University, the New York metropolitan area has long been a magnet for biomedical research. But the Big Apple's high cost of living and souring image is making it increasingly hard for that magnet to attract and retain talent.

Last autumn, the deans of the city's medical schools joined with assorted city and state officials and with captains of real estate, finance and the pharmaceutical industry to form the Commission on Biomedical Research and Development. Working under the auspices of the New York Academy of Medicine, the Commission is supposed to find ways to heighten the attraction.

One local group that is already working on the problem is the Aaron Diamond Foundation, a major supporter of medical research in the city. The Diamond Foundation is spending $\$ 16.6$ million on a new postdoctoral research fellowship program. Two months ago, the foundation named its first group of 25 fellows who will work for up to three years in the fields of AIDS or drug addiction research with a mentor at one of New York's research institutions.

The fellowships offer an attractive financial package: an annual stipend beginning at $\$ 36,000$, an annual research allowance of $\$ 25,000$ and an institutional allowance of $\$ 5,000$. Yet the number of applications it received was fewer than expected, and there were few takers outside the metropolis.

Just 73 researchers completed the application process, 61 of whom were already working in New York. Of 25 awards, only two went to researchers working outside of the city.

The foundation is modifying its criteria to attract more applicants from outside New York. Researchers will henceforth be required to request work with a mentor or institution with whom they have not worked during the past three years, or to explain why they need further training where they are.

Even so, the program must combat the fact that, for many people, living in New York is not an attractive idea. "I would definitely not raise a family in New York City," says Andrew Henderson, a native Californian who is working at Columbia University's College of Physicians and Surgeons under a grant from the US National Institutes of Health (NIH). Henderson cites such disincentives as the cost of housing in Manhattan, high state and city taxes and the strain of living among such urban problems as crime and homelessness. "In California you're in your car, you're sheltered," says Henderson, who rides the sub- way to Columbia each day.

On the other hand, the fellowships give researchers who want to remain in New York an opportunity to launch their careers. Diamond fellow JoAnn Difede, who expects to receive her doctorate in psychology from the New School for Social Research in the spring, thought about leaving New York because of the high cost of living. Instead, she will study psychoimmunology with a mentor at Cornell University Medical College. "There's a much better chance that I'll stay in New York now", she says.

The Diamond fellowships are intended in part to close a gap in funding left by the

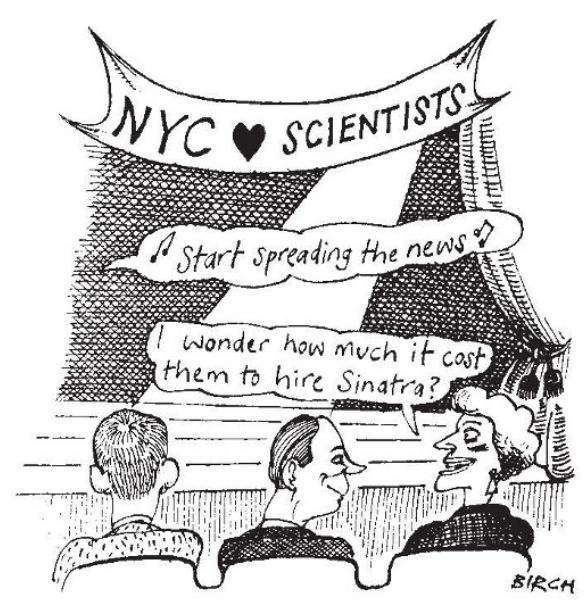

New York City Health Research Council. The council was formed in the early $1960 \mathrm{~s}$ and given $\$ 8$ million a year - a dollar for every New Yorker - to fund as many as 200 young scientists at a time.

But the program fell victim to the city's fiscal crisis in the mid-1970s. Its successor, the New York State Health Research Council, spends just $\$ 1$ million a year on fellowships spread throughout the state.

While John A. Rowe, president of Mount Sinai School of Medicine and chairman of the Commission on Biomedical Research and Development, insists that "biomedicine is not in crisis", the state conducts a declining proportion of the nation's overall biomedical research. According to a study by the Greater New York Hospital Foundation, New York's share of NIH funding fell from 8.1 per cent in 1970 to 6.6 per cent in 1987.

Another indication of the problem is found in a report of a few years ago by the New York State Health Research Council. Although the state has 12 medical schools, compared with four in Massachusetts and eight in California, those states beat New York in the competition for NIH post-doc grants, training grants, fellowships and small business innovation grants.

New York State slipped by another measure during the late $1980 \mathrm{~s}$, according to the Institute for Scientific Information. The number of scientific papers published by New York State researchers from 1985 to 1990 , in comparison to the previous five-year period, rose by less than half the rate of the nation as a whole. At the same time, the quality of their work remained high: New York researchers recorded a 16 per cent growth rate for citations, compared with an average increase of 10 per cent for all states.

No one questions that New York still has many attractive features. In addition to the myriad cultural opportunities, researchers like the fact that they have a network of colleagues at other teaching hospitals "within a ten-minute ride of here," says William A. Polf, deputy vicepresident of Columbia University Health Sciences.

But back in their own labs, researchers tend to find quarters tight. At Mount Sinai, for example, revenue from research grants and contracts has risen in the last three years alone from $\$ 48$ million to $\$ 73$ million. Yet there has been no significant increase in space for two decades. The school has vacancies for several department chairs, according to Rowe, but cannot fill them until it acquires more space.

Some institutions are expanding. Rockefeller University is completing a 14-story building, while New York University is putting up a new $\$ 163$ million biomolecular sciences building and Columbia is erecting a \$28 million facility with assistance from the city and state. Besides housing university labs, Columbia's new building will make space available to new biotechnology companies.

Columbia's would be the first incubator space for biotechnology in the city, which trails Boston, Washington, and San Francisco as a birthplace for such companies. The Commission on Biomedical Research and Development is studying the problem on the theory that the lack of significant commercial activity may be stifling the growth of biomedical research.

The Commission has also asked the Louis Harris polling organization to survey winners of Federal grants nationwide to learn how young researchers make their decisions about where to work. The plan is to use that information to attract more of them to New York.

"There's a need for a wake-up call," says Rodney Nichols, chief executive officer of the New York Academy of Sciences. "New York cannot any longer assume that its number one status is guaranteed for life."

Mimi Bluestone 